\title{
Analysis of Labor Requirement Provision of Medical Record File Based on WISN to Effectivity of Medical Record Distribution Service to Polyclinic
}

\author{
M Dana Prihadi ${ }^{1}$ Teguh Redy Senjaya ${ }^{2}$, Laras Ayu Santika ${ }^{3}$ \\ 1,2,3 Akademi Perekam medis dan Informatika Kesehatan Bandung \\ Email:danaprihadi@apikesbandung.ac.id
}

\begin{abstract}
Based on the preliminary study there are several problems related to the provision of medical record files (1) Polyclinics with different deviation chambers of the floor. (2) Tracer that sometimes errors. (3) The distribution officer concurrently serves as the officer providing medical record documents. The purpose of this research is to know the needs of workers who provide medical record file documents based on WISN calculations to support the effectiveness of work in the distribution of medical records to Polyclinics at RSUD "45" Kuningan. The method used is descriptive qualitative and data collection techniques that are through direct observation, interviews and reference studies that have close relevance to the subject matter. The conclusion of this study, namely: (1) SPO is appropriate, (2) The effectiveness of medical record distribution services has not been effective, (3) The needs of officers as many as 9 people with a description of 3 officers providing medical records and 6 distribution officers.
\end{abstract}

Keywords: Provision, Distribution, Medical Record File, WISN, Effectiveness.

\section{INTRODUCTION}

Filing is one of the important components in medical records where it must be done by competent human resources in order to improve the quality of health services in patients and filing officers effectively in the process of implementation. The filing officer is responsible for the medical record documents that have been recorded, processed and then stored again in the filing section. The number of filing officers in a health service, especially in hospitals should be adjusted to the number of patient visits every day in order to produce maximum service.

In addition, the existence of adequate human resources is expected in the process of implementing the services provided will produce good effectiveness and impact on patient satisfaction so as to improve the quality.

RSUD "45" Kuningan is one of the hospitals under the auspices of the Government of Kuningan Regency that has been accredited B (Paripurna) located on Jl. Jend. Sudirman No. 68 Kuningan. How to store medical record documents in the hospital is by centralization method but previously using a decentralized system that is a document outpatient medical records are separated from hospitalization.

Through the observation conducted on April 12 14, 2018 at RSUD "45" Kuningan it is known that out of the 30 samples studied the average provision of outpatient medical record files is $>10$ minutes where the minimum service standard is $\leqslant 10$ minutes, so that there is a discrepancy with service standards. This is likely because the filing personnel consists of 5 people, 3 people take medical records in the closet and 2 people are tasked with taking the file in the closet and distributing the medical record file to each polyclinic.

The number of polyclinics in rsud "45" Kuningan is 16 polyclinics. The average daily visit of patients to polyclinics is about 420 visits. The high number of patients, especially outpatients and the large number of polyclinics resulting in the workload of personnel providing medical records and distribution files at RSUD "45" Kuningan is still too much. When viewed from the discrepancy in the number of documents Medical records with the number of officers providing medical records and distribution files that exist, resulting in the distribution of documents Medical records become late in addition to the distance between the storage room Medical records with polyclinics different floors and too far then hampered also if the tracer that is in the storage room occurs error. This condition results in a high risk of fatigue, hampered and delayed to the services to be provided in each polyclinic.

Based on the background of the above problems, the problems that will be reviewed are:

1. What is the procedure of medical record distribution activities at RSUD "45" Kuningan?

2. How is the effectiveness of medical record distribution services at RSUD "45" Kuningan?

3. What is the labor needs of the officer to provide medical record documents based on WISN to support the effectiveness of work in document distribution services to Polyclinics at RSUD "45" Kuningan? 


\section{THEORETICAL FRAMEWORK}

Medical records (Huffman, 1994) are "recordings or notations of who, what, why, when, and how services are provided to patients during the treatment period, in which they also contain knowledge about the patient and the services obtained including containing sufficient information to identify the patient, verify diagnosis and cure and store the results." (Savitri, 2011:2)

Gemala R. Hatta (2013:73), in the Health Information Management Manual in Health Care Facilities, "medical records are documents containing notations and files on patient data, examinations, healings, steps and other services in patients in health care facilities or institutions."

Regulation of the Minister of Health (PERMENKES) No. 269 of 2008 concerning medical records states "medical records are documents containing notations and documents about the patient's identity, examination, healing, treatment, other services that have been received by the patient." Patients are individuals who consult their health problems to obtain the necessary health services directly or indirectly to certain doctors or dentists and/or health personnel. Note / notation is the writing of the doctor or dentist about the steps taken on the patient in order to heal or perform services to the patient. The document is a capture of certain events of doctors, dentists, and/or health personnel, including other supporting groups such as supporting examination results, observation and treatment writings, as well as photographs of radiology examination activities, imaging images and electro diagnostic recordings.

When medical record personnel will determine the way used in storage activities, it is good to know what way to use in the storage of files in the health agency.

According to the Ministry of Health of the Republic of Indonesia Directorate General of Medical Services (2006:80), there are two ways of storing medical record documents:

a. Centralization

This centralization means the storage of the patient's medical records by uniting all patient records and other records during the patient's treatment.

b. Decentralization

By decentralizing the document of outpatient medical records separated from hospitalization.

Savitri (2011:95) types of medical record file storage systems include:

1) Alphabetic storage system

That's how to store by sorting alphabetically. The patient's first name letter is used as a letter key in tracking on storage racks. This type of storage takes a long time to work and has a high vulnerability that causes considerable errors, such as changed names and misspelled names. Another drawback of this system is that medical record personnel must carefully look at the order of letters carefully on the patient's name.

2) Numeric storage system

A file storage type with numeric is a type of medical record file storage by following the order of the medical record numbers. There are 3 numeric ways, namely:

3) Straight numerical filing system

Also called a paralleling system with a direct number that is where medical record documents are lined up based on the order of medical record numbers directly on the storage shelf. For example, the following three medical records will be stored sequentially in one rack, i.e. 04-00-01, 04-00-02, 04-00-03.

Advantages of direct number system storage type:

a) Make it easier to retrieve documents with consecutive medical record numbers without pausing some numbers.

b) Make it easier to train medical record personnel who must carry out the storage work.

Disadvantages of this type of storage system direct number:

a) Allow medical record personnel to be crammed into the same shelf, if the documents taken are documents that have just been stored on the storage shelf.

b) Medical record personnel should look at all medical record number numbers because it is often a misplaced saving.

2) Middle digit filing system

Middle digit filing system is a way of storing documents by using the middle number. The trick is that the medical record documents are aligned based on the order of medical record numbers seen from the 2 numbers of the middle group. The number located in the middle becomes the first number, the number located on the left becomes the second number sequence and the rightmost number becomes the third number sequence.

Table 1

Example of a Central Number System

\begin{tabular}{|c|c|c|}
\hline 8 & 2 & 0 \\
\hline $\begin{array}{l}\text { Number } \\
\text { Group } \\
\text { Second }\end{array}$ & $\begin{array}{c}\text { Number Group } \\
\text { First }\end{array}$ & $\begin{array}{c}\text { Number } \\
\text { Group } \\
\text { Third }\end{array}$ \\
\hline
\end{tabular}

Advantages of central number system storage type:

a) The process of retrieving 100 medical record documents whose numbers are sequential will be easier.

b) Switching to the middle number system is easier.

c) The group of 100 medical record documents with sequential numbers on the direct number system is exactly the same as the group of 100 middle number systems.

d) In the middle number system the spread of numbers is more evenly distributed on the storage rack, when compared to with a direct number system, but still does not match the final number system.

e) Storage personnel, can be done division of tasks in other storage parts, so that storage errors can be prevented. 
Lack of storage type of middle number system:

a) Need more education and training.

b) Gaps occur in the section, this happens if the document is moved to inactive storage.

c) The middle number system cannot be used to the maximum on numbering more than two numbers.

3) Final number system (Terminal digit filing system)

Terminal digit filing system is a system of storing medical record document numbers through the final number system. This is done through the juxtaposition of documents on the filing rack by means of medical record documents lined up based on the order of the last group's medical record numbers. That means the last two group numbers are used as the key to keeping the medical records file.

Table 2

End Number System Example

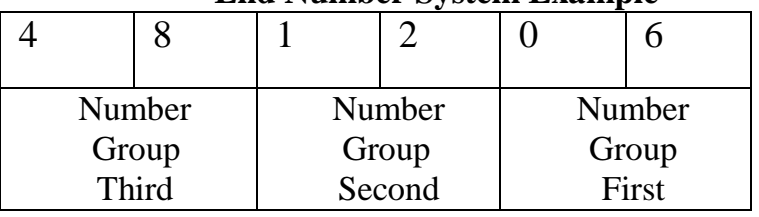

The advantages of this type of system are:

a) The addition of the number of documents will be spread evenly to 100 groups in the storage cabinet. Medical records personnel are not crammed into one storage area.

b) Medical record personnel may be held accountable in a number of special sections, e.g. there are 6 officers each assigned: sections 00-20, sections 21-41, sections 42-62, sections 63-83, sections 84-104, and sections $105-125$.

c) The task will be evenly divided because each personnel performs a job with almost the same number of documents every day per part.

d) Decommissioned documents can be retrieved from the shelf in each section, even when adding new documents in the same section.

e) The number of documents for each section is supervised and can avoid empty shelves.

f) The number of documents is controlled, thus helping to facilitate the planning of storage equipment (number of shelves).

g) Misfile errors can be avoided.

Disadvantages of final system storage type:

a) Education and training will take longer than using the direct number system.

b) The initial cost will be required to be greater because it must provide shelves first.

4) Chronological storage system

This system is a type of medical record file storage based on the sequence of events of patients coming to fasyankes (health care facilities). For example, in the fasyankes of storing medical record documents through the way of sorting dates, so that a group of dates will be formed for treating patients. This system is suitable in small scope category fasyankes, e.g. in private practice doctors, specialists, and midwives.
Table 3

Examples of Chronological Storage Systems

\begin{tabular}{|l|l|l|l|l|l|}
\hline 0 & 1 & 0 & 1 & 0 & 1 \\
\hline \multicolumn{2}{|c|}{$\begin{array}{c}\text { Sequence } \\
\text { numbers in } \\
\text { one day }\end{array}$} & \multicolumn{3}{|c|}{ Service date } & \multicolumn{3}{|c|}{$\begin{array}{c}\text { Month of } \\
\text { service }\end{array}$} \\
\hline
\end{tabular}

Human resources (HR) is a very important aspect and should not be separated from organizations, institutions or companies. Human resources are the most important part of strengthening the development of the organization. In principle, this human resource is a human being assigned to an organization with the functions of mobilizers, idea loaders and who plan to achieve the goals of the organization.

KEPMENKES RI Number: 81/MENKES/SK/I/2004, WISN (Work Load Indicator Staff Need) is an indicator that shows how much manpower is needed, in this study is a health facility, through workload calculation, which then the allocation of human resources is more rational and easy to apply.

The method of calculating human resources needs based on workload (WISN) is a way of determining / calculating the needs of health human resources based on the real workload performed by each category of health workers in each work unit. The advantage of WISN method is that it is easy to operate, easy to use, easy to implement technically, comprehensive and in accordance with reality.

The calculation method based on this method is:

1) Perform available work time assignments

The goal is to obtain the working time of each part of human resources who work in fasyankes / hospitals for one year.

On the basis of the data, the calculation of time assignment is then made available in the following ways:

Available Work Time $=\{\mathrm{A}-(\mathrm{B}+\mathrm{C}+\mathrm{D}+\mathrm{E})\} \mathbf{x F}$

Where:

$\mathrm{A}=$ Working day, based on law or provisions on fasyankes.

$\mathrm{B}=$ Leave within one year, adjusted employee rights rules (12 working days).

$\mathrm{C}=$ Education and training, in accordance with the applicable provisions in the Hospital.

$\mathrm{D}=$ National Holiday in accordance with the agreement with the Minister.

$\mathrm{E}=$ Absence of work due to illness, absence of work with /without giving info.

$\mathrm{F}=$ Working time, in accordance with the regulations applicable in fasyankes.

2) Determining the division of work as well as the class of human resources

The goal is to obtain work and class divisions that have responsibility for the implementation of individual health service activities to patients, families, and communities inside and outside the hospital. 
Data required in the determination of work divisions and hr classes:

1. Hospital Organizational Structure Chart including toxic description of each division and sub-division of work.

2. Decision of the Director of the hospital regarding the establishment of structural and functional work divisions, for example: Medical division, Quality Control division, Other Fields/Sections.

3. Personnel data in each division of work is seen from education.

4. Law No. 36 Th. 2014 concerning Health Workers.

5. PERMENKES RI No. 33 year 2015 concerning human health resources.

6. Legislation related to the functional position of health human resources.

7. Professional provision standards, standard service provisions and standard operating procedures (SOP) of the hospital's work division.

3) Preparation of work load standards (SBK)

SBK is a quantity of work expenses within one year per class of human resources. SBK a basic work is prepared based on the time of completion of the task (average time) and the duration of work available and owned by each class of human resources.

Data and information for the determination of workloads of each class of human resources:

1. The class of human resources working in each division of the hospital work as the results are in the second step.

2. Standards of professional provision, standards of service provisions set and applicable in hospitals.

3. The average time requirement of each class of human resources in completing various services.

4. Data and information on service activities in each division of work.

Standard workload = (work time awailable)/(average time per prineipal activity)

Required data:

a. Business hours are available.

b. Organizational structure chart.

c. The main activities and responsibilities of each class of human resources.

d. Average time in the completion of various main activities.

e. Professional standards.

f. Set the time based on the agreement.

g. The average time to complete the main activities is obtained from:

a. Reference of research results.

b. Conduct research.

c. Recording time in completing the description of activities (based on SOP)

4) Making loose standards

The goal is to obtain a leeway factor in each class of human resources that includes the type of activity and the need for duration in the completion of an activity that is not directly related.
The creation of loose standards can be done by means of observations and interviews to each class of related human resources:

a. Activities that are not directly related to the service, for example: training, seminar activities, making activity reports, preparation of medical needs, etc.

b. How often each activity (units of days, weeks and months).

c. The need for average time in completing activities.

Standard allowane $=$ (average time per leeway foctor) $/($ uptime available $)$

5) Determining human resources needs per-unit

The calculation of human resource needs per division of work aims to obtain the amount and type of human resources needed in the efforts to organize health activities and develop within one year. (MINISTRY OF HEALTH, 2004:40)

On determining the needs of human resources per unit work required:

a. Data from the previous step are:

- Work time available

- Standard workloads and

- Standard allowance for each HR category

b. The number of principal activities per division of work within one year.

Formula:

Hr Requirement $=$ (quantity of principal activities $) /($ workload standard $)+$ allowance standare

Data requirements:

a. Available work time.

b. SBK

c. Standard allowance for each class of human resources.

d. Number of principal activities per division of work for one year.

Effectiveness is a benchmark that describes the reach of a target. It is more output-oriented whereas input is not very attentive. If efficiency is associated with effectiveness, although there is an increase in effectiveness, efficiency does not necessarily increase anyway.

The dimensions of this effectiveness relate to the acquisition of maximum and optimal work, in the sense of achieving targets related to quality, quantity and time. While the dimensions rather than efficiency relate to the efforts to compare inputs to the realization of their use. The explanation informs that productivity is seen as a whole, meaning that the output created is the result of the acquisition of the overall inputs in the organization. Such inputs are usually referred to as production factors. The output created is obtained from inputs through the process of activities in the form of products or services. These production factors can be in the form of labor, capital, raw materials, science and technology as well as energy.

Quality is a measure that describes how much value has been met from all conditions, specifications and 
desires. This concept can be only limited to input in its orientation, or output or both. Quality is also related to the process of production activities which will have an influence on the optimal results and mal value that the whole wants to achieve.

\section{METHODOLOGY}

The method in this study is used qualitative method that is to systematically describe "Analysis of Labor Needs Calculation of Provision of Medical Record Files Based on WISN On The Effectiveness of Medical Record Distribution Services to Polyclinics in RSUD "45" Kuningan".

Qualitative method is a way of research based on thinking through the philosophy of post-positivism, which is usually used to examine the state of objects that are natural, (this is contrary to experimentation) the position of researchers as a core / key instrument, data collection used is by means of triangulation (combined), analysis of data is inductive with results that lead to qualitative rather than combined.

Research activities are conducted with the beginning through the collection of data directly and as is. Therefore, researchers are directly confronted and present at the location, situation and data sources that become observation objects. Researchers do not use numbers, but descriptive data is collected in the form of descriptions to find meaning and meaning, although they do not reject the existence of numbers to support research activities. By examining each filing officer's activities from the start of the provision of outpatient medical records are then distributed to each polyclinic.

The total sampling quota to be studied is 5 filing officers from the total population is 5 people. However, from the total sampling quota, researchers will use sampling techniques for activities carried out by filing officers by calculating the number of outpatient medical record documents from outpatient visits. In this case, the author determined the number of samples studied was taken 100 files for 5 filing officers consisting of each officer 20 files

\section{DISCUSSION}

The observations illustrate, in the procedure of sending medical record documents (distribution) at RSUD "45" Kuningan, the procedures carried out are in accordance with and in accordance with the Standard Operational Procedures (SPO) in force and those in the hospital.

The purpose of sending medical record files (distribution) is as a reference steps in the implementation of the delivery of medical record documents to the service unit so that the delivery of medical records is done correctly so that no leakage of patient secrets, and patient secrets can be maintained properly.

The procedure of medical record distribution service to Polyclinic begins after the registration of outpatients and then exits the tracer, searches for medical record documents as well as retrieves medical record documents that are on the storage shelf and then distributed to each polyclinic of each destination listed on the tracer.

In the search for the patient's old medical record documents, if it is not found and has been searched for 15 minutes but still not found, then the medical record personnel will re-issue the new medical record documents. If the old document is found before the service on polyclinics, the old document is proposed and combined at that time also in the destination polyclinic. However, if the old documents are found after the patient service is completed, the documents will be combined when they return and are in the installation of medical records.

As for new patients, new medical record documents are available in each polyclinic in order to facilitate and speed up the process of outpatient services.

The description above provides an overview and can be concluded that the conditions in the field of research on the procedure of sending medical record documents (distribution) at RSUD "45" Kuningan are in accordance with the existing rules. Seen from the conformity to the existing SOP and apply.

The results of further research by researchers on the effectiveness of medical record distribution services can be seen from the bar chart below, where the field conditions are higher than the Minimum Service Standard.

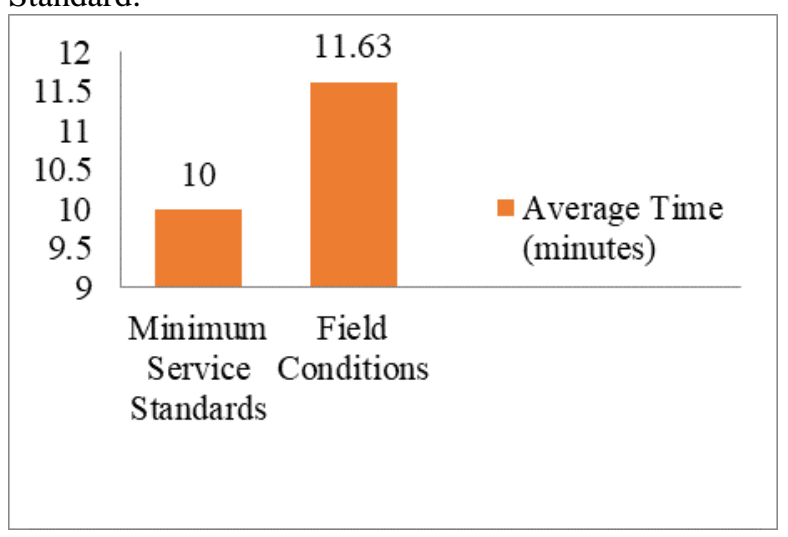

Figure 1 Comparison of Average Service Time

The bar graph above can be known the average duration of provision of medical record documents is 11.63 minutes while in the standard of minimum hospital service the standard is $\leq 10$ minutes. It can be said that in the process of providing medical records documents of outpatients that are then distributed less effectively because it exceeds the standard time that has been set is $\leq 10$ minutes.

This is due to several aspects, including the tracer that came out of error so that in the process of providing outpatient medical record documents became hampered. Changes in the implementation of the new SIMRS, there are other obstacles in the process of searching medical records files, namely the emergence of a 
double No.RM so that in the search for files was done 2 times search. If the old No.RM is not found on the storage rack means that it is in the new No.RM according to the new SIMRS and vice versa.

In addition, the location of storage space with different polyclinic floors that resulted in the mileage traveled was far enough so as to impact the speed of delivery of medical record files. This can also lead to the risk of fatigue and decreased performance of officers in distribution activities so that services to be provided in polyclinics become hampered and delayed. Another factor that can influence this is the lack of human resources for distribution officers consisting of only 2 people. Distribution officer at RSUD "45" Kuningan in addition to the task of distributing medical record files to each polyclinic, has another task that is to conduct searches as well as retrieve medical record documents from the storage cabinet.

So from some of the factors above effectiveness in the distribution of outpatient medical records to polyclinics is still not effective that has an impact on the satisfaction of services received by patients. This study provides information that the results for the provision of medical record files required 8 people human resources while the existing human resources 5 people then lack 3 human resources. The distribution section is needed 6 people while the existing human resources only as the provision of medical record files then the lack of 6 human resources. Total human resources needs are 14 people with details such as the above. This is obtained from calculation results using WISN whose formula is the result of the division between the number of activities in 1 year with the standard workload plus the standard time allowance.

It can be concluded that the needs of human resources, especially for filing officers by using WISN protection is needed as many as 9 people. With details of 3 officers providing medical records and 6 people for distribution officers.

The lack of human resources can have an impact on the effectiveness of outpatient services in hospitals because it can hinder and slow down services. In accordance with the results obtained that the existing service time is 11.63 minutes while according to the Minimum Service Standard is not more than 10 minutes.

\section{CONCLUSION}

Based on the results of the above research regarding the Calculation Analysis of Labor Needs for the Provision of Medical Record Files based on WISN on the Effectiveness of Medical Record Distribution Services to Polyclinics at RSUD "45" Kuningan, it can be concluded that in terms of Standard Operating Procedures, officers provide Medical Record files and distribution. in carrying out its duties in accordance with applicable standards and procedures. Regarding the effectiveness of outpatient medical record distribution services to the polyclinic it is still not effective, because the processing time obtained from the calculation using WISN is 11.63 minutes while according to the Hospital Minimum Service Standard it is $\leqslant 10$ minutes. Regarding the need for officers to provide medical record files and distribution, from the results of the calculation of the WISN method there were 14 people, while the officers in RSUD "45" Kuningan were only 5 people so there was a shortage of 9 people with a description of 3 officers providing medical record files and 6 distribution officers.

\section{REFERENCES}

[1] Arikunto, Suharsimi. 2010. Research Procedure of a Practical Approach. Jakarta: Rineka Cipta. p. 152

[2] Budi, Savitri Citra. 2011. Medical Record Work Unit Management. Yogyakarta: Quantum Synergistic Media. pp. 2, $73-114$.

[3] Ministry of Health, Directorate General of Medical Services. 2007. Guidelines for The Implementation and Procedure of Medical Records of Hospitals in Indonesia. Jakarta. pp. 13, 80 - 139.

[4] Ministry of Health, Directorate General of Medical Services. 2007. Guidelines for The Implementation of Hospital Services. Jakarta. pp. 15 - 16.

[5] Ministry of Health, Directorate General of Medical Services. 2007. Minimum Hospital Service Standards. Jakarta. p. 94

[6] Hatta, R.Gemala. 2013. Health Information Management in Health Care Facilities. Jakarta: University of Indonesia (UI-Press). p. 73.

[7] Notoatmodjo, Soekidjo. 2010. Health Research Methodology. Jakarta: Rineka Cipta. p.87

[8] Sedarmayanti. 2009. Human Resources and Work Productivity. Bandung: CV.Mandar Maju. pp. 52 60.

[9] Sevilla, Consuelo G., et al. 1993. Introduction to Research Methods. Jakarta: University of Indonesia (UI-Press). pp. 161-162

[10] Sugiyono. 2017. Quantitative, Qualitative, and R\&D. Research Method Bandung: Alfabeta,cv. pp. 80 - 85, 145 